\title{
Deep disagreement and hinge epistemology
}

\author{
Chris Ranalli ${ }^{1}$
}

Received: 9 April 2018 / Accepted: 21 September 2018 / Published online: 6 October 2018 (c) The Author(s) 2018

\begin{abstract}
This paper explores the application of hinge epistemology to deep disagreement. Hinge epistemology holds that there is a class of commitments-hinge commitments-which play a fundamental role in the structure of belief and rational evaluation: they are the most basic general 'presuppositions' of our world views which make it possible for us to evaluate certain beliefs or doubts as rational. Deep disagreements seem to crucially involve disagreements over such fundamental commitments. In this paper, I consider pessimism about deep disagreement, the thesis that such disagreements are rationally irresolvable, and ask whether the Wittgensteinian account of deep disagreement-according to which such disagreements are disagreements over hinge commitments - provides adequate support for pessimism. I argue that the answer to this question depends on what hinge commitments are and what our epistemic relation to them is supposed to be. I argue for two core claims. First, that non-epistemic theories of hinge commitments provide adequate support for pessimism. Nevertheless, such theories have highly implausible consequences in the context of deep disagreement. Secondly, at least one epistemic theory of hinge commitments, the entitlement theory, permits optimism about such disagreements. As such, while hinge epistemology is mainly pessimistic about deep disagreement, it doesn't have to be.
\end{abstract}

Keywords Deep disagreement · Hinge propositions · Rational resolutions · Epistemic entitlement · Belief · Epistemic reasons · Worldview · Wittgenstein · Hinge epistemology

\section{Introduction}

Consider disagreements over whether the Earth was created by God less than 10,000 years ago (so-called young Earth creationism), or over the worldview expressed

$凶$ Chris Ranalli

ranallicb@gmail.com; c.b.ranalli@vu.nl

1 Department of Philosophy, Faculty of the Humanities, Vrije Universiteit Amsterdam, De Boelelaan 1105, 1081 HV Amsterdam, The Netherlands 
by the Berkeleyean triad of theism, immaterialism, and idealism; or over the extreme variants of the so-called New World Order conspiracy theory, in which nefarious beings have been systematically and radically deceiving us with respect to not only major historical and political events, but also our general beliefs about the world, such as that we don't live in a simulation. ${ }^{1}$ These are ordinarily taken to be deep disagreements because they seem to be systematic disagreements rooted in contrary worldviews. ${ }^{2}$

One influential way of thinking about deep disagreements has its roots in Wittgenstein's (1969) On Certainty. ${ }^{3}$ A major theme of On Certainty is that rational evaluation generally presupposes a fixed set of commitments for any agent. These are the so-called general "hinge commitments" of rational evaluation: the fundamental presuppositions of one's worldview which make one's rational evaluations, such as the evaluation of a belief as justified, intelligible to us (see Pritchard 2016, p. 70. cf. Coliva 2015; Wright 2004b).

To see this idea in practice, imagine a disagreement between a skeptic about the past, who thinks that we have no evidence against the hypothesis that the Earth was created only minutes ago, and a geologist, who seems to issue claims inconsistent with the skeptic's view, routinely making epistemic claims about the distant past, like 'we know that those boulders are millions of years old'. We can easily imagine the geologist marshalling evidence from the fossil record and various abductive considerations against the skeptic's claim. As Coliva (2015) observes, however: "geological beliefs about the specific age of the Earth could only be justified by taking for granted that the Earth had existed for a very long time. Only that way could fossils and other evidence be brought to bear on the issue of the specific age of the Earth" (Coliva 2015, p. 1). Mutatis mutandis for the disagreement between the geologist and the young Earth creationist. They'll disagree over the age of the Earth, and they'll seem to marshal reasons for their contrary views as well. The application of the Wittgensteinian idea here is that the reasons they offer for their positions presuppose more basic commitments about the existence of the Earth. In the geologist's case, that it's a naturally occurring phenomenon, stretching into the distant past. In the young Earth creationist's case, that it's not only a naturally occurring phenomenon, and that it doesn't stretch into the distant past. Instead, it's cosmologically very young.

What I will call the Wittgensteinian account of deep disagreement says that deep disagreements are disagreements over the hinge commitments of one's worldview. ${ }^{4,5}$ In this paper, I want to explore whether the Wittgensteinian account of deep disagreement supports pessimism about such disagreements: that they cannot be rationally

\footnotetext{
${ }^{1}$ See Barkun (2003).

2 See Hazlett (2013, p. 13).

${ }^{3}$ Hazlett (2013), Feldman (2005), Fogelin (2005), Lynch (2016), and Pritchard (2011b).

${ }^{4}$ A note about the terminology here. Some authors use 'framework proposition' to refer to the same thing, such as Fogelin (2005). Wright (2004b), on the other hand, uses 'cornerstone proposition'. I'll follow Pritchard (2016) and use 'hinge commitment' instead of 'hinge proposition' where necessary, because it's a matter of philosophical controversy whether the hinges are propositions. Moreover, while I'm considering many specific theories of hinge commitments in this paper, I'm not considering all of them, but rather a cluster of representative cases.

5 This view has been recently considered by Fogelin (2005), Feldman (2005), Hazlett (2013), Lynch (2016), and Pritchard (2011b). See also Adams (2005), Campolo (2009), Phillips (2008), and Turner and Wright (2005).
} 
resolved. I will argue that the Wittgensteinian account provides adequate support for pessimism about deep disagreement on so-called non-epistemic accounts of hinge commitments. On this view, hinge commitments aren't subject to rational evaluation and otherwise lack epistemic properties (Pritchard 2011a, 2016). I argue that while non-epistemicism supports deep disagreement pessimism, the theory has several implausible consequences, and thus casts doubt on whether we should understand hinge commitments non-epistemically. I will then consider a mainstream epistemic theory of hinge commitments, according to which hinge commitments are subject to rational evaluations and can possess certain epistemic properties. Specifically, I argue that the entitlement theory of hinge commitments (Wright 2004a, b, 2014) permits certain kinds of rational resolutions for disagreements over hinge commitments and thus deep disagreements so understood.

Let me clarify what I mean by 'rational resolution' in this context. There are at least three different senses in which a disagreement might be rationally resolvable. One way implies that the disputants rationally reach agreement on the target proposition:

Rational resolvability: A and B's disagreement over $p$ is rationally resolvable if and only if there is some doxastic attitude $\mathrm{D}$ that $\mathrm{A}$ and $\mathrm{B}$ can jointly take to $p$ which is the (uniquely) rational attitude for $\mathrm{A}$ and $\mathrm{B}$ to have towards $p$.

This is the sense of 'rational resolvability' implied, I submit, by our ordinary conception of rationally resolving a disagreement. To see this, consider two siblings who disagree over whether their half-sister is due an equal share of their mother's inheritance. One sibling believes that their half-sister is due an equal share, split three ways between them, while the other sibling disagrees. Imagine the half-sister asks the pro-equal share sibling whether she has resolved the disagreement with her anti-equal share sibling, and she replies: "we've resolved our disagreement, but we continue to disagree". This clearly sounds infelicitous. Indeed, the infelicity is retained even if the pro-equal share sibling filled in the details as follows: "We continue to disagree, because she believes that she has good reasons for being against you receiving an equal share, while I still think that I'm reasonable in believing that you should get an equal share of the inheritance. Nevertheless, we've resolved our disagreement, since we agree to disagree". Intuitively, they haven't rationally resolved their disagreement. Rather, they've merely identified good reasons to continue to disagree.

Contrast this with the following:

Rational Response: $\mathrm{A}$ and $\mathrm{B}$ rationally respond to their disagreement over $p$ if and only if there is some doxastic attitude $\mathrm{D}_{\mathrm{A}}$ that $\mathrm{A}$ takes to $p$ which is the (uniquely) rational attitude for A to take to $p$, and there is some doxastic attitude $\mathrm{D}_{\mathrm{B}}$ that $\mathrm{B}$ takes to $p$ which is the (uniquely) rational attitude for $\mathrm{B}$ to have to $p$.

This is the sense of 'rational resolvability' which mainstream epistemology of disagreement has in mind. It is the sense in which the disputants adopt the (uniquely) rational attitude towards the target proposition, even if the resulting attitudes are different, such that they continue to disagree. ${ }^{6}$ Finally, we have:

\footnotetext{
6 What I am calling 'rational resolvability' and 'rational response' corresponds to the distinction Matheson (2018) calls a strong rational resolution and a weak rational resolution to a disagreement. See also Feldman
} 
Rational Persuasion: A rationally persuades B to adopt A's doxastic attitude D to $p$ if and only if there is a set of premises accepted by A that A can appeal to in an argument that rationally ought to persuade $\mathrm{B}$ into adopting $\mathrm{D}$ towards $p$ (and vice versa).

Compare with Lynch (2016) on the relevant sense of rational persuasion: "you rationally persuade someone of some proposition when you move her to change her commitment-state on the basis of a reason that would make sense internal to her perspective" (Lynch 2016, p. 252). The thought here is that you rationally persuade your opponent in a disagreement if you offer them your reasons for adopting your attitude to the proposition, and they appreciate that this reason counts towards taking the attitude that you have and subsequently change their mind to match your attitude in light of this fact.

With these distinctions in play, we can distinguish between different sorts of pessimists about deep disagreement, corresponding to each of these distinctions. The core pessimist I will be interested in here is moderate: they say that deep disagreements are not rationally resolvable in the first sense. The modest pessimist, by contrast, says only that deep disagreements are not resolvable by way of rational persuasion. The radical pessimist holds that disputants cannot even rationally respond to deep disagreements. Moreover, each of these pessimists hold that deep disagreements are specifically not epistemically rationally resolvable in their intended senses, even if they are practically or prudentially resolvable (e.g., the disputants might have good practical or prudential reasons from which they can rationally reach agreement, or rationally respond to their disagreement). For ease of exposition, when I speak of the pessimist, I will be referring to the moderate pessimist, unless I state otherwise. However, I will argue that the proponent of the Wittgensteinian account of deep disagreement who accepts the nonepistemic theory of hinge commitments is committed to pessimism in all three senses: that they are epistemically rationally irresolvable, and neither subject to epistemically rational responses nor rational persuasion.

Here's the structure of the paper. In Sect. 2, I explain what the Wittgensteinian account of deep disagreements is and why it provides a prima facie case for pessimism about deep disagreement. In the remaining parts of the paper, I explore how the different ways of developing the theory of hinge commitments can have a serious impact on whether the Wittgensteinian account adequately supports pessimism. To this end, in Sects. 3 and 4, I explore two non-epistemic theories of hinge commitments: the non-propositional theory (Sect. 3) and the non-belief theory (Sect. 4). I'll argue that they entail radical and moderate pessimism - that such disagreements lack rational responses as well as rational resolutions-and otherwise face serious objections. In Sect. 5, I argue that the entitlement theory of hinge commitments fails to support both moderate and radical pessimism about deep disagreement, thereby opening a window of optimism for hinge epistemology. Finally, Sect. 6 considers some objections and replies.

Footnote 6 continued

(2005, pp. 16-17), and Kappel (forthcoming), Sect. 3. I am indebted here to an anonymous referee for their very helpful suggestions on the different senses of rational resolution in play. 


\section{Hinge commitments and pessimism}

We can summarize the basic case for pessimism about deep disagreement on the basis of the Wittgensteinian theory as follows:

(P1) Deep disagreements are disagreements over hinge commitments.

(P2) Disagreements over hinge commitments are rationally irresolvable.

Therefore,

(C) Deep disagreements are rationally irresolvable.

Call this the Wittgensteinian Argument for pessimism. The first premise is simply an expression of the Wittgensteinian theory of deep disagreement. However, we need to draw a distinction here between direct and indirect deep disagreements. We should understand (P1) as saying that direct deep disagreements are disagreements explicitly over hinge commitments. For example, if you and I disagree over whether there is an external world and other related claims, we are engaged in a direct deep disagreement, on this picture at least. Indirect deep disagreements, by contrast, are in the first instance disagreements which in some way commit the disagreeing parties to directly disagreeing over a hinge commitment. ${ }^{7}$ Such a case arises when, for instance, your reasons for holding your view commits you to directly disagreeing with someone over a hinge commitment, such as when your disagreement over a geological claim with a conspiracy theorist leads to a disagreement about the significance of fossil evidence, which, in turn, leads to a disagreement over a hinge commitment about the reliability of scientific methods. Since my main question is about whether the Wittgensteinian theory adequately supports deep disagreement pessimism, I will bracket whether (P1) is true. It suffices that the theory is taken seriously by contemporary epistemologists as a theoretical starting point for our thinking about deep disagreement (Fogelin 2005; Feldman 2005; Hazlett 2013; Lynch 2016). ${ }^{8,9}$

\footnotetext{
7 An interesting question I don't explore here is how disagreements over questions which somehow depend on hinge propositions rather than disagreements over hinge propositions directly might be different. For example, even if disagreements over induction is reliable are rationally irresolvable, plausibly disagreements over questions which turn on that the reliability of induction will be subject to rational resolutions or rational responses. Thanks to an anonymous referee for raising this question. Relatedly, disagreements over how to rank fundamental epistemic principles might be subject to rational resolutions even if disagreements over the truth of those principles are not. See Kappel (forthcoming) and Lynch (2016) for this.

8 You might worry that some cases of deep disagreement don't look like cases of disagreement over or involving hinge commitments. It suffices that some deep disagreements are understood as disagreements over hinge commitments. For example, if you think —-following Lynch (2010) and Kappel (2012) — that deep disagreements are disagreements over fundamental epistemic principles, that is strictly consistent with some such principles being hinge commitments. Indeed, this is plausible in the case of induction is reliable, among others. The Wittgensteinian account says that deep disagreements are always disagreements over hinge commitments, even if not every disagreement over a hinge commitment is a deep disagreement. Finally, the Wittgensteinian account can be seen as more liberal than the fundamental epistemic principle account of deep disagreement, since (1) it seems like disagreements over fundamental metaphysical principles can amount to deep disagreements, but crucially (2) it's not clear how the fundamental epistemic principle account could explain why such cases are deep disagreements. The extent to which the Wittgensteinian and the fundamental epistemic principle accounts are different is explored in Ranalli (forthcoming).

9 Although I am not arguing for (P1) in this paper, I think it can be motivated by way of thinking about cases of deep disagreement. For example, when we consider cases like the conspiracy theory disagreement, it's not only a disagreement over contrary fundamental epistemic principles, but crucially over many interrelated
} 
The second premise says that disagreements over hinge commitments are rationally irresolvable. I want to pause here to consider two glaring concerns. The first is what, exactly, hinge commitments are. The second is whether the premise is even prima facie plausible. As we'll see, these two concerns are intimately connected. On the first point, hinge commitments are philosophically controversial in the following respect: philosophers don't agree on what it is to be a hinge commitment, even though they tend to agree on which commitments are hinge commitments. So, for example, here's a fairly representative list from Brueckner (2007):

There is an external world, sense perception is reliable, I am not a brain in a vat, my faculty of reasoning is reliable, the Earth is more than three minutes old, testimony is reliable, memory is reliable (Brueckner 2007, p. 285).

The list isn't exhaustive. There is supposed to be some reliable criteria for identifying which commitments of ours are hinge commitments. And this will turn on one's theory of hinge commitments. As we will see, there are many (jointly inconsistent) theories of hinge commitments. ${ }^{10}$ What they have in common, however, is that the hinge commitments are in some way not subject to the same sorts of epistemic evaluations that your ordinary beliefs are subject to (e.g., your beliefs about the weather, about where you work, etc.). Roughly, your hinge commitments are your most basic 'fixed points' in your worldview. They are supposed to be what makes reason-giving possible - that is, they are supposed to make it possible for, say, your visual experience of the downpour outside to count as a reason to believe that it's currently raining, and for someone who might retort "well, that's actually your neighbor watering the flowers with a large water bucket" to count as a reason to doubt whether your initial belief is true (more on this in Sects. 3-5). ${ }^{11}$ Your hinge commitments are what enable that person's doubt to be intelligible as a reasonable doubt and for your initial belief to be intelligible as a reasonable belief. How they do this, of course, is a matter of philosophical controversy. ${ }^{12}$

This reason-giving property of hinge commitments makes it hard to see how they could also be within the space of reasons. After all, the thought is that by enabling the reason-giving relation, they lie outside the space of reasons: for the question of what reasons you have to accept or deny hinge commitments is a category mistake, as they are what make reason-giving possible. However, there is a tension here with the intuitively plausible claim that many historical and contemporary philosophers have

\footnotetext{
Footnote 9 continued

metaphysical, epistemic, and normative commitments. The Wittgensteinian view is arguably well-placed to explain this. However, since I will be arguing that on many non-epistemic and epistemic theories of hinge commitments, there are several implausible consequences in the context of disagreement, this might be evidence against the view that deep disagreements should be understood as disagreements over hinge commitments in the first place.

10 For an excellent overview, see Pritchard (2011a).

11 See Coliva (2015), Pritchard (2016), and Wright (2004b) for this way of thinking about hinge commitments.

12 As a quick case study: Wright (2014) thinks that your hinge commitments perform this role by virtue of you being epistemically entitled to trust them. So, your visual experience is a reason to believe that it's raining only if you're epistemically entitled to trust that sensory experience is reliable. Coliva (2015), by contrast, thinks that you only need to assume that sensory experience is reliable.
} 
rationally argued for what look like hinge commitments that they believed. The external world realist, like Moore, argued that there is an external physical world. Likewise, certain sorts of idealists, like Berkeley, denied this. In short, they disagreed with each other. The same can be said of proponents of other minds and the uniformity of nature, among others. If we take this at face-value, then it looks like epistemic reasons can be given for these sorts of views, and thus it's an open question whether we can rationally resolve disagreements over them. What, then, might adequately support (P2)?

Consider non-epistemicism about hinge commitments, the thesis that "rational support for our hinge commitments are impossible" (Pritchard 2016, p. 71, cf. Pritchard 2011a, p. 531). On this theory of hinges, they aren't in the space of epistemic reasons: that is, they aren't in the market for being evidentially believed (you lack evidence in favor of their truth or falsity), rationally believed (you lack epistemic reasons to believe or deny them), or propositionally known (you cannot know them). If non-epistemicism is true, I think it would provide a very powerful case for $(\mathrm{P} 2)$ of the Wittgensteinian argument. We can express the sub-argument for (P2), then, as follows:

Non-epistemicism: For any hinge commitment $H$, necessarily, it's not the case that there is any epistemically rational attitude that one ought to take to $\mathrm{H}$. That is, you are neither justified nor unjustified in taking any doxastic attitude towards $\mathrm{H}$.

Rational Resolution: A disagreement over $p$ is rationally resolvable only if there is some doxastic attitude $\mathrm{D}$ that the disputants can jointly take to $p$ which is the (uniquely) rational attitude that they ought to take towards $p$.

Therefore, substituting a hinge commitment for $p$ :

Pessimism: For any disagreement over a hinge commitment H, necessarily, it's not the case that there is an epistemically rational resolution to the disagreement.

Call this the argument from non-epistemicism. The argument is certainly valid. First, non-epistemicism says that there is simply no possible epistemically rational attitude you ought to take to a hinge commitment $H$. This entails: if you and I somehow disagree over a hinge commitment-say you believe it's true while I believe it's false-then non-epistemicism implies that neither of us are epistemically rational here. Secondly, the rational resolution premise says that any epistemically rational resolution for a disagreement consists in the disagreeing parties taking the (uniquely) rational attitudes they ought to take to the relevant content, in light of their disagreement, such that they reach agreement. So, suppose you and I disagree over whether $\mathrm{H}$ is true. If nonepistemicism is true, then since the object of our disagreement is a hinge commitment, it follows that there is no epistemically rational attitude that we could take to that content. Whether we both believe, or you believe, and I suspend, among the other possible combinations of attitudes we might take, it follows that none of them would be epistemically rational. ${ }^{13}$

\footnotetext{
13 More precisely, non-epistemicism is the thesis that: for any rational agent $\mathrm{A}$, and hinge commitment $\mathrm{H}$, it's not the case that there is an epistemically rational (as opposed to practically rational) attitude that you ought to take to H. Following Friedman (2013), if we think of suspending judgment as a cognitive attitude subject to epistemic norms, then the conclusion of the non-epistemicism argument would rule out suspension of judgment as well. However, if we think that suspension of judgment is not a cognitive attitude, then it doesn't rule this out.
} 
The next question we should ask, then, is whether the premises of the nonepistemicism argument are true, or adequately supported. The rational resolution premise is, I think, highly plausible. For what else would an epistemically rational resolution to a disagreement $b e$ in this case if not the disputants taking the epistemically rational attitudes that they ought to take towards the content for which they disagree, such that they reach agreement? ${ }^{14}$ One might think that a rational resolution for a disagreement is a resolution reached by paradigmatic rational means, that is, by way of our appreciation of the reason-based arguments for or against a view. By 'reason-based argument', what I have in mind are arguments in the informal logician and philosopher's sense: where reasons ${ }^{15}$ are explicitly offered as premises for a conclusion. This corresponds to the rational persuasion sense of resolving a disagreement. However, the argument from non-epistemicism supports not only that there are no epistemically rational resolutions to disagreements over hinge commitments, but that disputants cannot even rationally respond to such disagreements, much less rationally persuade each other. After all, if I believe the hinge commitment while you deny it, non-epistemicism implies that neither of us are being epistemically rational here because our attitudes to hinge commitments are essentially arational. According to non-epistemicism, it would be a kind of category mistake to try to epistemically regulate your attitude to a hinge commitment, say, by way of appreciating the evidence, or respecting epistemic norms. For our attitudes to hinges aren't subject to epistemic norms, epistemic reasons, or evidence. And if our attitudes to hinge commitments are neither epistemically rational nor irrational (because they are arational), then of course I cannot appeal to an argument that I accept which rationally ought to get you to adopt my belief. ${ }^{16}$ In this way, non-epistemicism together with the possibility of disagreement over hinge commitments leads to the surprising conclusion that disputants cannot even rationally respond to their disagreements over hinge commitments. As such, non-epistemicism supports not only moderate but also radical pessimism.

\footnotetext{
14 This is the sense of rational resolution that Lynch $(2010,2016)$ and Kappel (forthcoming) have in mind. Of course, there are other senses of rational resolution as well (see Sect. 1), but as we'll see, the nonepistemicism premise seems to rule out rational responses and rational resolutions to disagreements over hinge commitments, and thus trivially excludes resolutions by rational persuasion.

15 I am using 'reasons' as normative epistemic reasons, and treating it inclusively: to include both good and bad normative reasons (or what Sylvan 2016 calls "operative epistemic reasons"). For example, that it's currently raining outside is typically good reason to believe that it's wet outside, whereas that I looked into my crystal-ball in which it appeared to me that it's currently raining outside is typically not a good reason to believe that it's raining outside—although I'm still treating it as a normative reason. Contrast this with slipping in the shower, and getting a concussion which causes me to believe that it's wet outside. This is not only not a good reason to believe that it's wet outside, but it's not a normative reason at all (cf. Kornblith 2015). This is a causal, or explanatory reason (Raz 2011). We can initially identify reasons by way of what you (would) offer in support of something you believe or plan to do (or would believe or do).

16 Of course, this is consistent with the idea that a person might successfully appeal to an argument which persuades their opponent into adopting the attitude they take to the hinge commitment. Moreover, it is consistent with the idea that the disputants might be able to respond to their disagreement practically rationally, or be in a position to persuade each other by way of practical or prudential reasons. I am presupposing here that even if non-epistemicism is true, this needn't entail that our attitudes to hinges aren't subject to practical norms or practical reasons.
} 
What about the non-epistemicism premise-why should we accept that premise? Wittgenstein himself seemed to think that non-epistemicism is true. In On Certainty, Wittgenstein said of the hinges that:

"I want to conceive it [the hinges] as something that lies beyond being justified or unjustified." (OC 359).

Why did Wittgenstein think this? The basic idea is that rational evaluation is essentially local: that intelligible doubt requires that some things are not doubted, and that intelligible belief requires that some things are not believed. Certain things are held fixed as unbelieved and undoubted so as to enable some things to be intelligibly believed or doubted. ${ }^{17}$ These are your hinge commitments. This is in contrast to the idea that the scope of your rational evaluation can be fully general, extending to anything you could believe (see Stroud 2000).

Intuitively, you might think that there is a tension between the role our hinges play in our worldviews and rationally resolving disagreement over them. For the hinges are precisely the sorts of things which make it possible for certain states of affairs, propositions, or beliefs to be evidence or reasons for other beliefs. In short, they make the space of epistemic reasons possible. And if that is right, it's hard to see how they could also enter into the space of epistemic reasons as objects of rational evaluation. The non-epistemicist, however, goes beyond this prima facie case and provides a principled reason for why the hinges are outside the space of epistemic reasons. To see this, we need to consider two different ways of developing non-epistemicism.

\section{Non-propositionalism}

The first way is non-propositionalism, the thesis that hinge commitments aren't truthapt, and thus not really propositions at all (Moyal-Sharrock 2004, 2016). Rather, the hinges are non-factual rules (Wright 1985). If non-propositionalism is true, I think it would adequately support the non-epistemicism premise, and thus the non-epistemic argument would be sound.

The argument is straightforward. First, the object of belief, disbelief, and suspension are propositions: that is, truth-apt contents. Secondly, non-factual rules are, by their nature, not truth-apt. Therefore, non-factual rules are not objects of belief or disbelief. Ipso facto, then, they are not objects of justified belief or disbelief. ${ }^{18}$

\footnotetext{
17 cf. Pritchard (2016), Part II, Sect. 3. He writes: "The picture that emerges is thus one in which all rational evaluation is essentially local, in that it takes place relative to fundamental commitments that are themselves immune to rational evaluation, but that need to be in place in order for a rational evaluation to occur" (Prichard 2016, p. 66).

18 Here's a worry: if $x$ is not truth-apt, you might think we can still suspend judgment about $x$ if suspension of judgment simply is neither believing nor disbelieving. And you might think this is precisely the right thing to do, that you shouldn't believe what you cannot believe. But this relies on the principle that if $\neg$ (you epistemically should believe that $x$ ), then $\neg$ (you can believe that $x$ ). Contraposed, we get: if you can believe $x$, you should believe $x$, which is clearly false. The point here is that even if both parties can suspend judgment over a hinge commitment in this minimal sense, it wouldn't follow that they have rationally reached agreement in suspension of judgment. Plausibly, you should suspend judgment on whether $x$ only if there
} 
A second argument appeals more generally to epistemic norms. First, it's plausible that only cognitive attitudes, attitudes capable of being true or false, are subject to epistemic norms. Secondly, no attitude we take to a non-factual rule could be a cognitive attitude simply because the object of the attitude is neither true nor false. Hence, it follows that non-factual rules are not subject to any epistemic norms. Thus, if non-propositionalism were true of hinges, then it looks like non-epistemicism would be true of them as well. Pessimism would be right around the corner.

Wittgenstein seemed to argue for non-propositionalism. He said that:

OC 494 "I cannot doubt this proposition without giving up all judgement." But what sort of proposition is that?...It is certainly no empirical proposition. It does not belong to psychology. It has rather the character of a rule."

OC 204 "Giving grounds... comes to an end;- - but the end is not certain propositions' striking us immediately as true, i.e. it is not a kind of seeing on our part; it is our acting, which lies at the bottom of the language-game."

In the first passage, he says that the hinge 'proposition' has the 'character of a rule'. Likewise, in the second passage, he describes the epistemic practice of giving grounds for what you believe or doubt. His suggestion is that this practice 'comes to end': intuitively, you wouldn't be able to keep offering new grounds for your belief or doubt without circularity or entering a regress. But Wittgenstein doesn't thereby go the foundationalist route here and argue that there are some propositions which are immediately justified for you and which are the justificatory source of anything else you justifiably believe or doubt. Rather, there are some actions you perform which manifests a sense of optimal certainty in your action, and the suggestion seems to be that this action is non-cognitive, and thus not amenable to truth or falsity.

In his Facts and Certainty, Crispin Wright develops non-propositionalism as follows: if a (putative) proposition is not amenable to evidence or justification, that is reason to think that it's not factual after all (see Wright 1985, p. 457). So, for example, if we can't find a way to justify ' $2+2=4$ ', on Wright's view that would be a sufficient reason to think that it's not truth-apt. He argues for the following factuality equivalence principle:

\section{Factuality Equivalence: F(D) if and only if $\diamond$ [justifiably believe(D)]}

That is, a content is true (or false) if and only if it is logically possible to justifiably believe that it is true (or false). It should be clear that the right-to-left conditional is plausible: $\diamond$ [justifiably believe(Ф)] $\rightarrow \mathrm{F}(\Phi)$. After all, if you can justifiably believe (D) then $(1)$ is truth-apt. How else could it be an object of belief-much less justified belief-if it weren't truth-apt? The left-to-right conditional, however, is less plausible: $\mathrm{F}(\Phi) \rightarrow \diamond[$ justifiably believe(D)]. While the principle plausibly retains the idea that some propositions might be false and yet justifiably believed-that is, it plausibly dispenses with infallibilism about justification-it also abandons the idea that some

Footnote 18 continued

is some way of being right or wrong about the matter, but in the case of hinge commitments — understood as non-factual rules - there is no way of being right or wrong about them. 
propositions might be true, and yet never justifiably believed — that is, it implausibly dispenses with unknowable truths or unjustifiable truths.

Another, more recent development of non-propositionalism, due to Moyal-Sharrock (2016), takes it that the hinges are non-factual rules and that our attitude to them are "animal certainties":

The nonpropositional nature of basic certainties is one with their being ways of "acting" and to their being "animal." Whether a hinge certainty starts out as instinctive or natural (e.g., our certainty of having a body) or is second-nature. [...] The hinge certainty verbalised as "I have a body" is a disposition of a living creature which manifests itself in her acting in the certainty of having a body (Moyal-Sharrock 2016, p. 105).

My main worry with the non-propositional theory of hinges in this context is that the proponents of the Wittgensteinian Argument shoot themselves in the foot. For they want to show that their theory of deep disagreement leads to moderate pessimism: the thesis that deep disagreements are rationally irresolvable. ${ }^{19}$ But if non-propositionalism is true, it's not so clear that you could even disagree over the hinges - for they aren't truth-apt. The token phenomenon would be rationally irresolvable at the cost of being impossible.

Now the non-propositionalist might reply as follows: "there can be disagreements in non-propositional attitude, and so we can easily preserve disagreement over hinges and thus deep disagreement". ${ }^{20}$ For example, consider the "New World Order" or "Illuminati" global conspiracy theory (henceforth NWO), according to which there is a nefarious, powerful global network of politicians, scientists, bankers, and industryleaders who are responsible for the major geo-political and many major natural and historical events. Proponents of this theory claim that there is an NWO; that we are thereby radically and systematically mistaken with respect to nearly all of our political and historical views. On the most radical variants, the claim is that we are in a matrix-like simulation, controlled by evil aliens, and that politicians are merely their puppets. Plausibly, that there is no such NWO entity is a hinge commitment: for we aren't radically and systematically deceived about our social, historical, and biological condition. Imagine two people meet, Alex, who accepts this conspiracy theory, and Carrie, who denies it. Where 'pro!' and 'con!' lexically represent their non-cognitive pro-/con-attitudes, we can characterize their seeming dispute along the following lines:

\section{CONSPIRACY THEORY DISAgREEMENT:}

Alex: Pro! NWO.

Carrie: Con! NWO. ${ }^{21}$

There are two points I want to make in connection with this way of understanding the NWO conspiracy disagreement case. First, Alex seems in some way to accept that

\footnotetext{
19 Indeed, a basic commitment of non-propositionalism is the non-epistemic thesis about hinge commitments, and as we have seen from Sect. 2, this view seems to adequately support the impossibility of disputants taking any rational doxastic attitudes to hinge commitments. So, non-propositionalism would also suffice for radical pessimism, in conjunction with the Wittgensteinian theory of deep disagreement.

20 See Ridge (2012) for discussion of disagreement in non-cognitive attitude. See also Stevenson (1963) and (1944).

21 For representing contrary non-cognitive attitudes as pro-/con-attitudes, see Chrisman (2012).
} 
the NWO conspiracy theory is true, while Carrie seems in some way to deny that it is true. The non-propositionalist, then, has to give a revisionary account of this: they have to say that Alex doesn't really accept that the NWO conspiracy theory is true, and that Carrie doesn't really deny that it's true. Rather, neither of them are making any mistake here, and thus their disagreement is, at best, faultless: for neither of them are making any alethic mistake (cf. MacFarlane 2014). Call this the revisionary problem.

Secondly, the non-cognitive pro-/con-attitudes to the non-factual contents don't seem to accurately capture Alex's or Carrie's attitudes to the NWO conspiracy theory. What is it to be 'pro!' the NWO conspiracy theory? One might think it is to approve of what the theory says, but this wouldn't accurately capture Alex's attitude here. For he doesn't necessarily approve of the existence of the NWO conspiratorial organization and the actions ascribed to them: he might sincerely disapprove of it. Perhaps Alex approves of the explanatory power of the NWO conspiracy theory, while Carrie denies this. But intuitively this doesn't accurately reproduce their attitudes either. You can approve of the explanatory power of a theory whilst sincerely denying the theory. For example, many philosophers are prepared to say that Berkeley's triad of theism, idealism, and immaterialism has a lot of explanatory power but nevertheless deny it because, despite its potential explanatory power, it's false and less explanatorily potent than other theories. In general, the problem here is that it's hard to recover the relevant epistemic, logical, and psychological properties of belief in the theory using some other non-cognitive pro-/con-attitude. Call this the obscurity problem.

How might the non-propositionalist respond to the revisionary problem? There are three responses on offer. First, they might accept that the disputants really would need to radically revise their conception of their psychological relation to the NWO conspiracy theory and their disagreement with each other. For Alex doesn't really believe the NWO conspiracy, and Carrie doesn't really disbelieve it either. Moreover, as much as they might think they are arguing for the truth of their positions, they couldn't really be arguing for such positions any more than you can argue for the truth of 'shut the door!' or 'hooray!'. The non-propositionalist could simply bite the bullet here. Secondly, they might try to account for the disagreement between Carrie and Alex by way of the idea that they won't tend to enter a debate and will see each other's divergent hinge commitments as not being live options, that is, as not something that either disputant could imagine being committed to. ${ }^{22}$ Even if this could account for the sense in which they disagree, however, it would still be the case that the disputants aren't making any alethic or epistemic mistake: for what they are committed to is neither true nor false, justified nor unjustified. Intuitively, then, they would still need to radically revise their conception of their disagreement: for intuitively Carrie believes that the conspiracy theory is false while Alex believes that it's true. But this way of thinking about their disagreement would be wrong.

Non-propositionalists might also reject that it's revisionary: for they could say that the non-factuality of what they in some sense 'accept' makes sense of why their disagreement is persistent. While this might be explanatorily powerful on one level of analysis, it's a total failure at the level of their personal psychology. Intuitively,

\footnotetext{
22 Cf. Williams (1985) on "relativism of distance". I am indebted to an anonymous referee of this journal for their helpful comments here.
} 
Carrie believes that she has good reason to reject the NWO conspiracy theory, and Alex believes that he has good reason to accept the NWO conspiracy theory. But if non-propositionalism is true, both of them are necessarily mistaken here: neither of those higher-order beliefs could be true.

How might the non-propositionalist respond to the obscurity problem? Naturally, they might explore other kinds of non-propositional attitudes which do a better job of recovering the mechanics of a doxastic disagreement than if they thought of cases like CONSPIRACY DISAGREEMENT as a conflict at the level of one person's pro-attitude on the one hand and the other person's con-attitude, on the other hand.

One proposal, from Moyal-Sharrock (2016), is to think of one's attitudes to the hinges, understood as non-factual rules, as "animal certainties". She says that:

Wittgenstein is describing what it is like to be basically certain; to have an attitude of basic certainty - and the answer is that it is like a way of acting or know-how or reflex action (like grabbing a towel from the towel rack without thinking). Here, "I have a body" is the expression of a nonpropositional attitude; a way of acting in the certainty of having a body, acting embodied (Moyal-Sharrock 2016, p. 104).

So, perhaps we can model the NWO conspiracy case as follows:

\section{CONSPIRACY TheORY DisagreEMENT 2}

Alex: Animal certain of NWO conspiracy theory.

Carrie: Animal certain of $\neg \mathrm{NWO}$ conspiracy theory.

One immediate problem to note with NWO CONSPIRACY DISAGREEMENT 2 is that we cannot apply negation to the NWO conspiracy theory: the sentence 'there is an evil NWO organization which radically and fundamentally deceives you' doesn't express a proposition to be negated, on the non-propositionalist picture. So, we would have to recast their alleged disagreement as follows:

\section{CONSPIRACY Theory Disagreement 2*}

Alex: Animal certain of NWO conspiracy theory.

Carrie: It is not the case that Carrie is Animal certain of NWO conspiracy theory. ${ }^{23}$

Now we should wonder whether CONSPIRACY THEORY DISAGREEMENT $2 *$ is a genuine disagreement. I think it is fairly clear that it isn't: for it's plausible that having some animal certainties, and someone lacking them or having some other animal certainties - that is, having different unreflective ways of acting - need not be a disagreement, but just a difference. Consider, for example, the difference between you reaching for the falling glass, while your friend notices the glass but simply doesn't reach for it. Is that a disagreement? Certainly not. Rather, it's a difference in how you both reacted. That is, you had different non-cognitive reactions. Why think of the CONSPIRACY THEORY DISAGREEMENT $2 *$ case any differently $?^{24}$

\footnotetext{
23 Relatedly, we could instead conceive of Carrie as having a contrary animal certainty, such as the animal certainty for the NON- CONSPIRACY HYPOTHESIS: that you aren't subject to a widespread, systematic conspiracy. Either way, the main point is unaffected.

24 cf. Ridge $(2014, \S 1.4)$ on 'disagreement in attitude'.
} 
A second problem here is that it's hard to see how 'disagreement in animal certainties' would generalize to paradigm cases of disagreement over hinge commitments. Consider the disagreement between the external world realist and the idealist. It's not clear how the realist or the idealist would differ with respect to their animal certainties here. What would it be for the idealist to no longer express animal certainties with respect to the existence of the external physical world? Surely they act the same as the realist, modulo their philosophical belief-reports, certain assertions in philosophical contexts, and technical philosophical inferences. But surely that difference is not what the non-propositionalist has in mind here. What the non-propositionalist has in mind is the security with which you ordinarily act in the world anyway, as when you instinctively avoid danger, or go to scratch an itch on your body: in the first case, you act with the certainty of there being other things; in the second case, you act with the certainty of you having a body. Yet the Berkeleyean idealist and Moorean realist, who seem to disagree over the nexus of propositions such as that theism is true, idealism is true, and immaterialism is true, have a disagreement which intuitively goes beyond what is encoded in their animal certainties. If the non-propositionalist understands their respective commitments on this score as some difference in animal certainty, then it looks like non-propositionalism has the unintuitive consequence that the Berkeleyean idealist and the Moorean realist don't disagree after all, if we accept that sharing animal certainties is sufficient for agreement, just as not sharing them or having contrary animal certainties would be, on this view, sufficient for disagreement.

Finally, even if we understood animal certainties as simply ability knowledge, or knowing-how, intuitively it still wouldn't be a disagreement either. That Alex has some sort of distinctive know-how in connection with the NWO conspiracy theory but Carrie lacks this know-how (or has some contrary know-how) doesn't even remotely look like a disagreement, just a difference. For example, that A knows how to ride a bike, but doesn't know how to drive a car, and that B doesn't know how to ride a bike, but knows how to drive a car, is not a disagreement between $\mathrm{A}$ and $\mathrm{B}$, but a difference in the ways they can act. So, analyzing animal certainties in terms of ability knowledge wouldn't do the non-propositionalist any good here.

\section{The non-belief theory}

In his recent (2016, forthcoming) work, Duncan Pritchard has developed a novel nonepistemic theory of hinge commitments according to which they are propositions, just not believable. Call this the non-belief theory. As with the non-propositional theory, this too would provide a route to non-epistemicism. After all, if believing (or any doxastic state) is not the sort of attitude you could take to a hinge proposition, then how could you justifiably believe or take some creedal attitude to a hinge proposition? Intuitively, you couldn't.

Why does Pritchard accept the non-belief theory of hinge commitments? His (2016) argument goes like this:

Normative profile of Belief: Beliefs (or any doxastic attitudes) are, in their nature, responsive to epistemic reasons. 
Non-epistemicism: Our attitudes to hinge propositions are, in their nature, unresponsive to epistemic reasons.

Therefore,

Non-belief Theory: Our attitudes to hinge propositions are not beliefs (and are thereby non-doxastic). ${ }^{25}$

The normative profile of belief premise is highly plausible. Beliefs seem to be necessarily subject to reasons and epistemic rationality norms, and the premise doesn't say that beliefs are only propositional attitudes subject to certain kinds of epistemic norms. So, it doesn't give a normative profile theory of belief, but rather says that it's a necessary condition of belief. Moreover, it doesn't say that beliefs are, by their nature, rational. Rather it says that it's in their nature to be subject to epistemic rationality norms. Together with the second premise, the non-belief theory clearly follows. Thus, the argument is valid. But the lacuna in the argument is the second premise, which expresses non-epistemicism about hinge propositions. And since the non-epistemicism argument is the main argument we have been exploring for pessimism about deep disagreement, we need to ask why Pritchard supports non-epistemicism.

Here's Pritchard's (2011b) argument for non-epistemicism:

(P1) All rational doubts are grounded in reasons.

(P2) In order for reason R to count as a rational ground for $S$ 's doubt in the proposition $p$, it must be more certain for $S$ that R than $p$.

(C1) So, those propositions which are most certain cannot be rationally doubted. (From P1, P2).

(P3) All rational beliefs are grounded in reasons.

(P4) In order for reason $\mathrm{R}$ to count as a rational ground for $S$ 's belief in the proposition $p$, it must be more certain for $S$ that R than $p$.

(C2) So, those propositions which are most certain cannot be rationally believed. (From P3, P4)

(P5) But all belief-systems must include propositions which are held to be optimally certain.

Therefore,

Non-epistemicism: One's belief-system requires the existence of propositions, the hinge propositions, which are optimally certain but which are nevertheless immune to rational doubt or rational support. (From C1, C2, P5). ${ }^{26}$

Premises (P2) and (P4) are controversial. Consider cases of undercutting defeat. Sometimes, I get a reason to doubt that some source of my belief that $\mathrm{P}$ is well-founded or reliable, and thus reason to withhold believing that P. But that doesn't mean that my reason for doubting that the source of my belief that $\mathrm{P}$ is more certain for me than $\mathrm{P}$ is itself. For example, it might be that my senses are something I trust very often, and right now I believe that the wall is red on the basis of my visual experience. Now my friend Jan tells me that there are some red lights shining on the wall which makes the

\footnotetext{
${ }^{25}$ For this argument, see Pritchard (2016, pp. 90-91). By 'doxastic attitude' I mean belief, disbelief, credence, and suspension.

${ }^{26}$ See Pritchard (2011b, p. 197).
} 
wall look red even though it's white. In this case, I might be less certain that a red light is shining on a white wall than I am that the wall is red, but Jan's testimony still undermines my belief that the wall is red. Intuitively, I should be less confident than I was prior to his testimony. So, (P2) needn't be true.

Likewise, (P4) is problematic for similar reasons. Intuitively, my reason for believing one thing — say, that I have hands right now — might be slightly more certain for me than I am in my reason for believing it: say, that I see that I have hands. For I might be far more confident in the fact that I have hands than that I see that I do right now. ${ }^{27}$ Indeed, the chicken sexer case illustrates this idea nicely. The chicken sexers are normally certain, for any chick they see, that it's male (or female), but they are less certain of why they believe this, that is, of what their reason is for so believing. Intuitively, they are less confident in their reason than the proposition it apparently supports. Still, we don't hesitate to say that they know that the chick is male (or female). So, I don't think Pritchard's argument is convincing.

In any case, the non-belief theory itself problematizes the idea of disagreement over hinge propositions. Consider first the intuitively plausible doxastic theory of disagreement, according to which disagreement consists in inconsistent doxastic attitudes (Marques 2014). Paradigmatically, this is the case when you believe that $p$ and you are knowingly confronted by somebody else who believes that $\neg p$. The doxastic theory doesn't say that only inconsistency in belief is necessary for disagreement, but rather inconsistency in any doxastic attitude. For example, if my credence in $p$ is .9, while your credence in $\neg p$ is .7 , the theory rightly predicts that we disagree (if only slightly). If the doxastic theory of disagreement is true, it would follow straightforwardly from the non-belief theory that you cannot disagree over hinge propositions. Now, you might think that this isn't right, because Pritchard's theory is explicitly about belief: that we cannot believe hinge propositions or their negations. But notice that the first premise of the argument for the non-belief theory, the normative profile of belief premise, applies just as much to any doxastic attitude as it does to belief. Take, for example, credence and suspension of judgment. Why think that belief is, by its very nature, subject to epistemic norms but that creedal states and suspension of judgment are not? Surely whether you epistemically ought to be confident to some degree that $p$ is subject to epistemic norms; and surely whether you epistemically ought to suspend judgment either way about whether $p$ is also subject to epistemic norms. ${ }^{28}$ So, the normative profile of belief premise can easily be modified to accommodate doxastic attitudes more generally.

In his (forthcoming), however, Pritchard maintains that the doxastic theory of disagreement is false (see Pritchard forthcoming: p. 2). On his view:

\footnotetext{
27 Compare with Pritchard (2018): "just as one cannot make sense of a rational basis for doubt of a hinge commitment, for the very same reason one cannot make sense of a rational basis for belief of a hinge commitment either. They provide, rather, the framework relative to which a rational evaluation, whether positive or negative, takes place. Such commitments are thus essentially arational" (Pritchard 2018, p. 10).

28 The claim I am making here is conditional: if you think that belief is subject to epistemic norms, then by parity of reasoning, you ought to think that doxastic attitudes generally, like credences or suspensions of judgment, are also subject to epistemic norms. So, this leaves it entirely open that someone could accept this claim whilst consistently denying that belief is essentially subject to epistemic norms.
} 
Rather than belief being what is necessary for a bona fide disagreement, what's required is rather a genuine conviction on each side (i.e., a conviction that $p$ that excludes agnosticism about the truth of $p$ ).

On Pritchard's view, then, there can be cases where you are convinced that $p$ and your opponent is convinced that $\neg p$, such that neither of you believe the corresponding propositions (or have any credence), and you nevertheless disagree.

Although Pritchard argues that there are no rationally grounded propositional attitudes to hinge propositions, I think the case is much worse than this. For I think that his view entails that you are irrational once you reflect on your commitment to hinge propositions. On his picture, you can simultaneously realize that you are convinced that, say, the Earth existed in the distant past, whilst also recognizing that you cannot believe this. So, this looks like a straightforwardly Moore-paradoxical commitment:

(1) The Earth existed millions of years ago, but I don't believe it.

Indeed, a Moore-paradoxical commitment is straightforwardly implied by the nonbelief theory and Pritchard's view that you lack an epistemically rational basis for the hinge propositions, namely that:

(2) The Earth existed millions of years ago, but I have no rational basis for this.

Likewise, the same problem arises for conviction:

(3) I'm convinced that the Earth existed millions of years ago, but I have no rational basis for this.

(3) looks like a confession of irrationality, rather than an expression of the agent's arationality. The non-belief theory says that (a) you cannot believe hinge propositions, because belief is, by its very nature, responsive to epistemic reasons, but that no cognitive attitude to a hinge proposition is responsive to epistemic reasons. Nevertheless, (b) you are committed to the truth of the hinge propositions, such that you can recognize this commitment and be convinced of the truth of the hinge propositions. Thus, it looks like the non-belief theory implies that, for any hinge proposition HP, you are committed to 'HP but I don't have any rational basis for HP', which is intuitively irrational. That is, while we can say that your truth-committed conviction attitude to the hinge proposition is not irrational but merely arational, nevertheless your commitment to that combination is irrational. There is a tension between the first-order and the higher-order attitudes, such that it intuitively looks irrational.

What I'm proposing is that if you are convinced that the Earth existed millions of years ago, while your conspiracy foe is convinced that it hasn't, then, given the non-belief theory, we ought to be able to recognize that we lack any rational basis one way or the other, and thus shouldn't be convinced as we are. To see this point more clearly, consider the following scenario:

NON-BELIEVERS: Jill has recently read Pritchard's work on the nature of hinge commitments, and has become an ardent believer in the non-belief theory of hinge commitments. Jane has also recently read Pritchard's work on the nature of hinge commitments, and has also become an ardent believer in the non-belief theory of hinge commitments. However, Jill and Jane were raised in very different 
communities. Jill was raised within a religious fundamentalist commune, while Jane was raised in an atheistic scientific community. Jill and Jane later meet at university and become friends. Now, Jill is thoroughly convinced that the Earth was created by a God, but Jane is thoroughly convinced that it wasn't. Since they both recognize that they have no rational basis either way, they are happy to say to each other, respectively: 'The Earth was/was not created by God, but I have no rational basis for this'.

Intuitively, the non-believers case suggests that Jill and Jane ought to give up their convictions, given their higher-order attitudes, namely, their beliefs that they lack any rational grounds for being convinced as they are.

To recap, we've been looking at what supports (P2) of the Wittgensteinian Argument, that disagreements over hinge commitments are rationally irresolvable. We considered the non-epistemicism argument for this premise: that because hinge commitments aren't in the market for rational belief or doubt, they aren't in the market for rational disagreement and thus rationally resolving such disagreements is impossible. I've argued that if the non-epistemicism argument is sound, then we have a good case for pessimism about deep disagreement. However, I've also argued that one major defense of non-epistemicism, the non-propositional theory, supports nonepistemicism at the cost of losing the possibility of deep disagreement, or else its fails to recover the mechanics of genuine disagreement in such cases. Additionally, the theory took on controversial commitments. I then turned to a second way of developing non-epistemicism, the non-belief theory, and argued that even if the theory permitted the possibility of deep disagreement, it looks like they would be rationally irresolvable. However, this theory seems to have problematic consequences as well. So, while the non-epistemicism argument appears to adequately support pessimism, non-epistemicism itself seems implausible. One might think that if non-epistemicism is rejected, (P2) of the Wittgensteinian Argument will be unsupported.

\section{Entitlement theory}

In this section, I will consider the entitlement theory of hinge commitments (Crispin Wright 2004a, b, 2014). According to the entitlement theory, hinge propositions are within the scope of rational evaluation, because we can have a default non-evidential entitlement to accept or trust hinge propositions, which is a positive epistemic status. I will argue for two claims. First, that insofar as agents can be entitled to trust competing hinge propositions, it will be possible for them to maintain their trust in these hinge propositions despite their awareness of their disagreement. As such, these types of disagreements have rational responses. Second, the entitlement account permits rational resolutions in certain kinds of non-ideal cases. These are cases in which there is no antecedent equilibrium in entitlement to trust. In these cases, rationally the person who antecedently lacked entitlement to distrust the hinge proposition but fails to do so ought to adopt trust. In this fashion, both moderate and radical pessimism fail to follow from the entitlement account. 


\subsection{Hinges as authenticity-conditions of cognitive projects}

In order to understand the entitlement theorist's account of hinge propositions, we need to understand two other concepts out of which the account of hinge propositions is built. The first is a "cognitive project" and the second is an "authenticity condition" of the cognitive project. A cognitive project is a question-procedure pair: a question and a procedure for answering that question. For example, consider the question "what is the weather like right now?". One procedure for successfully answering this question is to use your visual perception in a certain way. This question-procedure pair defines your cognitive project in this case. An authenticity condition is what needs to be true or otherwise accepted as true in order for the target procedure to be legitimate way of finding out the answer to the question. For example, in the case of the weather, that your perception is reliable is an authenticity condition for your use of perception to be a legitimate way of finding out what the weather is like.

Hinge propositions are general authenticity conditions: the authenticity conditions that are "common to a large sweep of cognitive projects of a given kind" (Wright 2014, p. 216). An implication of this account of hinge propositions is that not all authenticity conditions of cognitive projects are hinge propositions. For example, an authenticity condition for finding out by sight whether the wall you see at an art exhibition is red is that there aren't any hidden red lights shining on a white wall. But it's certainly not a hinge proposition that there are no hidden red lights shining on the wall of that exhibition. ${ }^{29}$ An example of a hinge proposition so understood would be a general authenticity condition which extends to multiple cognitive projects. For example, suppose you're interested in (i) what your friend is thinking at some time but also (ii) whether your other friend is feeling any pain after a recent visit to the dentist. In both cases, you might start by asking your friends: 'what are you thinking about right now?', and 'how are you doing? Is there any leftover pain or swelling?' Asking these questions and getting answers to them looks like a good way of satisfying your cognitive projects here. The entitlement theorist maintains that, as an authenticity condition on the success of your procedures (understood here as knowledge- or justification-producing), is that there are other minds. And since such an authenticity condition is plausibly common to many cognitive projects, it's a hinge proposition.

What are the grounds of one's entitlement to accept hinge propositions, the general authenticity conditions of our cognitive projects? Wright's idea is that insofar as you have formed beliefs on the basis of certain grounds (e.g., evidence, or certain beliefforming processes), then there will be authenticity conditions for relying on those grounds in order to rationally form beliefs. In turn, there is a question about the epistemic status of these authenticity conditions. On the one hand, Wright thinks that doubting them should systematically lead you to doubt many other non-hinge propositions:

Such a doubt will be a doubt which ought—rationally—to ramify into a more general doubt of some sort: a doubt about any investigation that uses some

\footnotetext{
29 Here's Wright explicitly: "Wittgenstein's metaphor of questions and enquiry as pivoting on 'hinges' raises the question, how to characterize the range of the propositions he seems to have had in mind-the 'hinge propositions' - and their role: how exactly does enquiry 'turn' on them? The examples in On Certainty are a mixed bag, but we can approach the kind of thing Wittgenstein seems to be gesturing at by focusing, first, on the notion of an authenticity-condition" (Wright 2014, p. 214).
} 
relevant apparatus or relies upon a certain kind of evidence, or a doubt about the good standing of all previous investigations of a certain kind, or about the very subject matter of a large class of investigations, or about the propriety of their methods (Wright 2014, p. 216).

On the other hand, Wright doesn't think that you can acquire evidence or anything which indicates that the hinge propositions, the general presuppositions or authenticity conditions of your cognitive projects, are true. To see this, consider that there is an external physical world. Suppose you believe that the nearby park which you can clearly see has some trees in it. Wright's view is that your evidence here is broadly perceptual and abductive. None of your evidence, however, guarantees that there are trees there, or that there is even a park there. In this case, you have some aggregate evidence E (your perceptual experience and your abductive, explanatory considerations), a belief that $\mathrm{P}$ (there are trees in the park here), a type of epistemic justification, and an authenticity-condition A (there is an external physical world). Now we need to introduce two characters who build a theory of the structure of justification around cases like this. The conservative holds that $\mathrm{E}$ justifies you in believing that $\mathrm{P}$ only if you have justification to believe ${ }^{30}$ that $\mathrm{A}$ which is independent of $\mathrm{E}$ (or anything in the same domain), while the liberal holds that E can justify you in believing that $\mathrm{P}$ as long as you lack reasons to doubt that A. You don't, in addition, need to be justified in believing that A before E can justify you in believing that P. (cf. Wright 2014, pp. 217-218).

One might think that conservatism about the structure of justification entails skepticism. For example, in our external world case, conservatism implies that you justifiably believe that $\mathrm{P}$ on the basis of $\mathrm{E}$ only if you have independent justification to believe A (there is an external world). We could easily conjoin that with $\mathrm{A}^{*}$ : that you aren't a brain-in-a-vat in which it seems to you that there is an external world. But how could you justifiably believe that $\mathrm{A} *$ is false independently of your justification $\mathrm{E}$ to believe that $\mathrm{P}$ and similar propositions? Here's Wright on this:

The difficulty with the 'heavyweights', or cornerstones - the big, general hinges of the ilk $[\ldots]$ is that the very possibility of independent investigation is itself shrouded in sceptical doubt [...] What cognitive project can I undertake in order to engage the question whether there is an external material world save one which assigns to my apparent perceptual experience the very evidential significance for which the existence of an external material world is an authenticity-condition? But, then, if, as conservatism may seem to require, I need to investigate that condition independently, I am stuck. (Wright 2014, p. 221).

However, Wright doesn't think that this entails that you lack epistemic justification which favors accepting that there is an external world: we can be "entitled to accept" that there is an external world, even if we lack evidence for it (Wright 2004b, p. 53). So, Wright's thought is that conservatism doesn't entail skepticism because there is a

\footnotetext{
30 As we'll see, Wright's type of conservatism about the structure of justification holds that you can't justifiably believe A (e.g., general authenticity-conditions - the hinge propositions), but you can justifiably trust A. It is of course open to one to be a conservative about the structure of justification without accepting Wright's specific form of it.
} 
type of epistemic justification, epistemic entitlement, which we have by default-as an epistemic right -independently of evidence and any sort of cognitive achievement. Entitlement for $p$ is thus a non-evidential reason to 'accept' that $p$ : "To be entitled to accept a proposition has no connection whatever with the likelihood of its truth" (Wright 2004b, p. 53). Why believe that we have entitlements to trust the hinge propositions? The main reason is connected with inquiry and the attainment of epistemic goods. The basic line of thought is that without a specifically default non-evidential right to trust the hinge propositions, such as that sense perception is reliable, induction is reliable, that the world isn't a simulation created by nefarious aliens, and so forth, is that it would be "cognitively disastrous" not to do so (Hazlett 2013, p. 6). For our ordinary beliefs on the basis of sense perception, induction, and so on, would be groundless, since it is conceded by entitlement theorists that we lack evidence for the hinge propositions. Moreover, entitlement theorists maintain that unless we trust that the hinges are true, it would stifle inquiry: we wouldn't be able to rationally engage in inquiry which makes use of sense perception, induction, or otherwise rationally form beliefs under the guise that the world isn't merely a simulation, and so on.

Are the hinge propositions true propositions? We might think so, as many of the propositions we want to count as hinges seem to be true propositions (e.g., there are physical objects, there are other minds, people exist, the world didn't come into existence five minutes ago, and so on). However, it's not at all obvious that the entitlement account is committed to this. For you might think that there can be false propositions which play the role of being general authenticity conditions of many cognitive projects. To see this, consider the following example:

Spirits: A is a religious person on a small, isolated island and has little contact with the outside world. She trusts that there are 'nature spirits' living in the forest and 'ancestor spirits' of deceased people. She acquired this trust by way of the testimony of her isolated community and their long history of trust in the veracity of certain intellectual authorities' views about the holy books and the testimony of elders who know the oral tradition. If she were to give up here trust in the existence of such spirits, she would be rationally required to change many of other beliefs, and to radically revise her epistemic practices. Moreover, A is very inquisitive, and has sought out evidence which could indicate that there aren't such spirits—-such as interpreting the holy texts for herself, asking the priests and elders in her community about the spirits, visiting sacred places in search of evidence, and so on. However, A is young, and her community is extremely isolated, and thus she hasn't been able to leave her community to seek out counter-evidence from outside sources.

In this case, it looks like $\mathrm{A}$ is entitled to trust that there are spirits, even if this is false. For that proposition is an authenticity condition for a diverse range cognitive projects she has and would undertake in her community. This is not to say that A couldn't lose her entitlement to trust this: for she might learn later, after leaving her community, that many people deny what she trusts, and she might find herself convinced by the evidence they present. In that case, she would intuitively lose her entitlement to trust what she does now. 
In what follows, then, I will suppose that entitlement theorists permit cases in which one is entitled to trust that $\mathrm{P}$ even though $\mathrm{P}$ is false. However, it's important to note that entitlement to trust doesn't arise only out of the prospects of avoiding cognitive disaster and satisfying one's cognitive projects. Rather, entitlement to trust demands what Hazlett (2013) calls "open question" and "anti-vice" requirements as well. The open question requirement links entitlement to trust with the absence of rebutting evidence: if the agent is entitled to trust $\mathrm{P}$, then she lacks evidence against P. This seems right. After all, it might be that the agent lacked entitlement from the beginning, due to the presence of unequivocal evidence against $\mathrm{P}$, or else counterevidence emerges later, such that the agent, even if she was initially entitled to trust $P$, loses this entitlement later on by becoming aware of the counter-evidence without any way of defeating it. To see this, imagine that the elders of her village are all pretending that there are spirits for the benefit of the children, and plan to tell her at a certain age, like all the children before her, that there aren't any spirits. Intuitively, she would no longer be entitled to trust that there are spirits after such an event. The anti-vice requirement links entitlement to trust with an absence of intellectual vices in one's adoption or retention of trust, such as not being dogmatic or credulous. For example, imagine that the elders explain their tradition and tell her that there are no nature or ancestor spirits, but she continues to trust that there are anyway. Furthermore, we can imagine that, as she gets older, she just avoids inquiring into the matter, sticking to her initial trust. Intuitively, this is intellectually vicious: for she's discounting relevant evidence she has no extant reasons to discount here.

\subsection{Entitlement to trust and disagreement}

Recall that entitlement for $p$ doesn't count at all towards the truth of $p$. And we apparently need such entitlements because without them inquiry would be rationally groundless. Now one might think that this makes it strange to combine entitlement with belief. Why should you believe that $p$ if you are merely entitled to $p$, since having such an entitlement bears no connection whatever to the truth of $p$ ? Wright recognizes this issue, and thus doesn't think that the attitude that entitlement is linked to is belief, but rather 'trust' or 'trusting acceptance':

Of course it is often, perhaps normally, irrational to confidently assume or take the truth of propositions on trust. But the basic insight behind the entitlement project-Wittgenstein's insight, I believe-is that all reflective enquiry, and all reflective cognitive accomplishment, is essentially situated in trusting acceptances, some general, others specific to the particular context of enquiry, for which we lack evidence. [...] It is in the nature of rational reflective inquiry that this should be so. [...] The accumulation of evidential reason to believe is possible only within the framework set by trusting acceptances (Wright 2014, p. 242). ${ }^{31}$

\footnotetext{
31 cf. "The attitude to the local hinges and cornerstones has to be one of non-provisional confidence if belief in the products is to be rationalized in turn. At the same time, it needs to be a rational attitude to take for reasons other than our possession of evidential support for the effectiveness of the methods concerned. This was the train of thought that led me to propose that any useful form of entitlement had to license rational trust" (Wright 2014, p. 226).
} 
Wright's point here is that even though we could believe hinge propositions, epistemically we shouldn't. ${ }^{32}$ So, if our attitudes to hinge propositions should be trust or trusting acceptance, we should ask whether trust is robust enough to be a disagreeing attitude. To see how this might work, let's return to a variation of the spirit case:

Spirit Disagreement: A is a religious person who grew up on a small, isolated island and has little contact with the outside world. She trusts that there are 'nature spirits' living in the forest and 'ancestor spirits' of deceased people. If she were to give up her trust in the existence of spirits $(\mathrm{P})$, she would be rationally required to change many of other beliefs, and to radically revise her epistemic practices. Moreover, A is very inquisitive, and has sought out evidence which could indicate that there aren't spirits - such as interpreting the holy texts for herself, asking the priests and elders in her community about the spirits, visiting sacred places in search of evidence, and so on. However, A is young, and her community is extremely isolated, and thus she hasn't been able to leave her community to seek out counter-evidence from independent, outside sources. $\mathrm{B}$ is a secular humanist, and she grew up in an experimental isolated secular humanist community, which teaches that there are no deities or other supernatural phenomena. As such, she trusts that there are no spirits $(\sim \mathrm{P})$. If she were to give up her trust in the nonexistence of spirits and other supernatural phenomena, she would be rationally required to change many of her other beliefs, and to radically revise her epistemic practices. Like A, she is very inquisitive, and has sought evidence which could indicate that there are supernatural phenomena, including entities like spirits. However, as B is young, and her community is extremely isolated as well, she hasn't been able to leave her community to seek out counter-evidence from independent, outside sources. On a chance encounter, $\mathrm{A}$ and $\mathrm{B}$ meet and become aware of their disagreement about whether there are spirits, among other issues.

The first question I want to ask about this case is whether they are engaged in a genuine disagreement. Now, we might think that, in virtue of their attitudes to inconsistent propositions, they are disagreeing. But it's not so clear that they are. On the one hand, the pair:

\section{DISAGREEMENT IN PROPOSITIONAL TRUST}

A trust that $\mathrm{P}$ (there are spirits).

B trust that $\sim \mathrm{P}$ (there are no spirits).

looks like a disagreement. It seems rationally non-cotenable-intuitively, you can't rationally trust that $p$ and trust that $\sim p$ at the same time-and at least one person seems to be at fault: for if one of them is right, this precludes the other from being

\footnotetext{
32 Many philosophers have criticized Wright's entitlement theory on the grounds that entitlement at best gives one prudential reason to trust that $p$, rather than a genuinely epistemic reason to trust that $p$. See Jenkins (2007), Pedersen (2009), and Pritchard (2016). For another defense of the entitlement theory, see Hazlett (2006). The sense of 'epistemic reason' that Wrightian entitlement captures is epistemically consequentialist: in certain cases, the epistemically right thing to do is to trust certain propositions, even though you lack evidence for them, as this can be expected to maximize the epistemic good (e.g., getting more knowledge, access to certain truths, and so on). See Hazlett (2014), Sect. 2 for a defense.
} 
right. But it's not clear that this is a genuine disagreement until we understand what propositional trust is. Compare with:

\section{DISAGREEMENT IN PROPOSITIONAL HOPE}

A hopes that $\mathrm{P}$.

B hopes that $\sim \mathrm{P}$.

In the same way as with propositional trust, at least one of them is at fault here: for this is guaranteed by the fact that their attitudes are directed at inconsistent propositions. Moreover, we might think that hoping that $p$ and hoping that $\neg p$ is rationally noncotenable: there is something odd about hoping both that, say, Real Madrid will win the match and that they'll lose the match. Yet, despite these facts, it's not clear that our second case is a disagreement. Imagine, for example, that you hope that Real Madrid will lose the match, while your friend hopes that they won't. It might be that you believe that they will win, however, since their track-record is impeccable, while your friend believes the same. It would certainly be odd to say that your differences in what you hope for constitutes a disagreement. Rather, it seems like you agree (given that you believe the same proposition), but you simply hope for different outcomes. ${ }^{33}$

We can extend this idea to the spirit disagreement case as follows. It might be that A trusts that there are spirits, while B trusts there aren't spirits, and yet they are both inclined to believe that there are spirits. Perhaps B was raised in a family which unknowingly retains some tendency towards belief in the supernatural, and has the right sort of psychological dispositions which make the existence of supernatural phenomena seem attractive. B of course trusts that there are no spirits. But she is, like A, nevertheless inclined to believe it.

This sort of case should be intelligible on Wright's picture of entitlement as rational trust. Wright himself maintains that entitlement to trust that $p$ doesn't entail entitlement to believe that $p$. Ipso facto, you shouldn't believe that $p$ if you're only entitled to trust that $p$, for then you would be believing without any evidence or anything which indicates that $p$ is true. So, cases where you trust that $p$ whilst disbelieving $p$ should be possible. Otherwise, Wright would need to say that such a case is impossible or else irrational, which would speak against the entitlement theory.

However, insofar as it is possible to have genuine disagreements in propositional trust, this raises the following questions:

(1) Can such disagreements be rationally responded to?

(2) Can such disagreements be rationally resolved?

Intuitively, if A and B are already rational in their attitudes prior to the disclosure of the disagreement, it's hard to see why there wouldn't be either a rational response or a rational resolution to their disagreement after disclosure. To see this, consider A and B in the spirit disagreement case. Let's distinguish between whether the disputants were entitled to their trust before the disclosure of their disagreement and after the disclosure of their disagreement. In this case, it seems as if, prior to the disclosure of their disagreement, both of them were entitled to trust the target hinge propositions of their respective worldviews. This is because each hinge proposition forms a constitutive

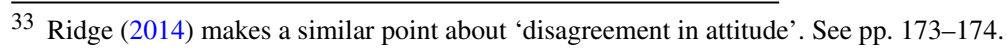


part of their worldviews and is otherwise embedded within their respective cognitive projects; giving them up would result in relative cognitive disaster, a radical revision to their epistemic practices. Moreover, neither of them seems to be intellectually irresponsible with respect to their trust. For neither of them has neglected inquiry with respect to the target hinge propositions - at least, within the scope of what should be expected from them in their circumstances-nor viciously continued to trust their hinge propositions in the face of apparent counter-evidence. As such, it seems as if each disputant is entitled to trust their respective hinge propositions prior to the disclosure of their disagreement. Of course, this doesn't tell us that after the disclosure of their disagreement, there is a rational response, such that there is a uniquely rational attitude $\mathrm{D}_{\mathrm{A}}$ for $\mathrm{A}$ to take to $\mathrm{P}$ and a uniquely rational attitude $\mathrm{D}_{\mathrm{B}}$ for $\mathrm{B}$ to take to P. But it's hard to see why there wouldn't be either a rational response or a rational resolution (a uniquely rational attitude $\mathrm{D}$ that $\mathrm{A}$ and $\mathrm{B}$ jointly ought to take to $\mathrm{P}$ ), since it has already been established that they rationally can take cognitive attitudes to the target propositions.

What I want to argue now is that, in the spirit disagreement case, A and B rationally ought to retain their trust. Thus, there is a rational response to their deep disagreement. However, I will later consider a variation of the case where A and B mutually ought to adopt the same attitude, in which case the entitlement theory also permits rational resolutions in certain cases.

While I've argued that prior to the disclosure to the disagreement, A and B were rationally entitled to trust contrary hinge propositions, it's not obvious that this verdict holds true after the disclosure of their disagreement. We might think this for one of two potential reasons:

HIGHER-ORDER UNDERCUTTING DEFEAT: the disclosure of their disagreement alone provides a higher-order undercutting defeater for their trust, since it indicates that at least one of them is mistaken.

REBUTTING DEFEAT: the presentation of their apparent first-order evidence against each other's respective hinge propositions during the disagreement are mutual rebutting defeaters against each other's trust in their respective hinge propositions.

If either of higher-order undercutting defeat or rebutting defeat are true, then intuitively the rational response to their disagreement in propositional trust is to mutually suspend their trust. ${ }^{34}$ As such, they would thereby rationally resolve their disagreement by rationally reaching agreement in suspension of propositional trust towards the target hinge propositions. So, two questions we should ask here are:

(Q1) After the disclosure of their disagreement, do A and B get a higher-order undercutting defeater for their trust?

(Q2) After the disclosure of their disagreement and the presentation of apparent counter-evidence, do A and B get mutual rebutting defeaters for their trust?

On Q1, you might think that disclosure of the disagreement alone provides an undercutting defeater for their entitlement to trust their hinge propositions. By comparison, many epistemologists hold that there is some intuitive force in the suggestion that once

\footnotetext{
34 Compare this with conciliatory views of peer disagreement. See Christensen (2007) and Feldman (2006, 2007).
} 
you become aware that you're engaged in a peer disagreement- that is, a disagreement with somebody just as likely as you are to evaluate the evidence correctly, or somebody in just as good of a position as you are to judge correctly in the case-you should conciliate, tending towards your opponent's view and your opponent towards your view. The thought is that evidence that you disagree with an epistemic peer is higher-order evidence that you made a mistake in that case. And to get such evidence in a case of deep disagreement, one would need evidence that their disagreement is with an epistemic peer.

Returning to the SPIRITS DISAGREEMENT case, however, it's hard to see how they could rationally maintain that they are epistemic peers of each other with respect to the existence of spirits and related topics, as they're in a position to rationally predict of each other that they would evaluate evidence pertaining to the relevant religious, historical, or even many ordinary events very differently, and in ways that they are likely to regard as not equally reliable. For example, if A rationally believes that B trusts that there are no spirits, she could rationally predict that B would believe that A's other religious, moral, and ordinary beliefs which turn on this dispute would also be judged as false. But if that's how B is likely to evaluate the evidence, why should A see her as her peer (and vice versa)? Of course, you might think that your belief about whether your opponent is your peer should to be independent of the current case and your initial verdict about the disputed proposition, namely, that you should bracket your own assessment of the present case in forming a judgment about whether they are your peer. ${ }^{35}$ But peerhood evaluation isn't plausibly independent of every salient feature in the current case. For it's precisely cases like SPIRIT DISAGREEMENT and others which, in one fell swoop, intuitively can give you strong evidence that your interlocutor isn't an epistemic peer of yours. So, it's not clear at all that in cases of deep disagreement so understood you get higher-order evidence that you've made a mistake, since it's hard to see how you could have good enough evidence for thinking that your opponent is your peer. So, it seems as if the rational response to the disagreement is for them to retain their attitudes of trust and thus continue to disagree. There would be a rational response, then, but not a rational resolution to the disagreement.

On Q2, we can reimagine the spirit disagreement case as follows, holding everything else from the original case fixed:

DIALOGICAL SPIRIT DISAGREEMENT: A and B meet and become aware of their disagreement about whether there are spirits. A presents what strikes her as strong evidence for the existence of spirits, such as the testimony of the people her community judges to be intellectual authorities and their holy texts. In turn, $\mathrm{B}$ presents what strikes her as strong evidence for the non-existence of spirits,

\footnotetext{
35 Christensen's independence principle is about how to regulate your first-order belief about the target proposition in response to a peer disagreement, rather than how to regulate your higher-order belief about whether your opponent is your peer. See Christensen (2009, p. 758). The principle I'm invoking specifically targets your higher-order belief about whether your opponent is your peer: roughly, that your assessment of whether they're your peer doesn't need to be independent of your present case, since their verdict in the present case is relevant evidence that rationally shouldn't be ignored. Compare Kelly's (2013) holocaust denier case. It seems rationally required that you not bracket facts about your present case with the holocaust denier in forming a belief about whether they are your epistemic peer, as that is evidence intuitively relevant to your assessment of whether they're your peer.
} 
such as the testimony of the people her community judges to be intellectual authorities and their secular humanist texts.

Notice that, on the entitlement account, both first-order evidence sets must be merely misleading evidence, since hinge propositions lack evidence. ${ }^{36}$ In turn, their presentation of their evidence as evidence against their opponent's view is at best a misleading rebutting defeater. Nevertheless, since neither disputant is aware of this fact about their apparent first-order evidence, we can sidestep this issue: it suffices that each disputant takes it that they have evidence which rationally ought to change their opponent's attitude into one which matches their own.

In any case, whether they rationally ought to change their attitudes here isn't independent of the question of whether they are epistemic peers, or rationally believe that they are. As before, A can rationally predict that B disagrees with her on many of the important related issues, and that B is likely to judge the evidence very differently than she is. Likewise, B can rationally predict that A disagrees with her on many of the important related issues, and that A is likely to judge the evidence very differently than she is. If that's right, then they both have evidence or have easy access to evidence which indicates that they're not epistemic peers. However, if they're not epistemic peers, then it's no longer clear that the mere presentation of their (misleading) evidence rationally ought to move them to change their attitudes. Rather, it seems as if they're rationally permitted to maintain their disagreement in trust. Hence, it's false that they get either a higher-order undercutting defeater from the disclosure of their disagreement, or mutual rebutting defeaters from the presentation of (misleading) counter-evidence, such that they rationally ought to withhold their trust in response. Instead, they're rationally entitled to maintain their trust in the face of their deep disagreement.

So far, I've argued that in cases of deep disagreement so understood, the entitlement theory permits rational responses, such that there can be a uniquely rational attitude $\mathrm{D}_{\mathrm{A}}$ for $\mathrm{A}$ to take to $\mathrm{P}$ and a uniquely rational attitude $\mathrm{D}_{\mathrm{B}}$ for $\mathrm{B}$ to take to $\mathrm{P}$, such as trusting that $\mathrm{P}$ and distrusting that $\mathrm{P}$ (or trusting that $\sim \mathrm{P}$ ). However, I think that there can be cases in which the disputants ought to agree as well, such that there can be a uniquely rational attitude $\mathrm{D}$ for both $\mathrm{A}$ and $\mathrm{B}$ to take to $\mathrm{P}$. For example, these will be cases in which both disputants are rationally entitled to trust a common hinge proposition, even if one them incorrectly fails to trust it for reasons that are independent of apparent evidence. To make this concrete, consider the following example:

INDUCTION DISAGREEMENT: $\mathrm{A}^{*}$ and $\mathrm{B}^{*}$ meet and become aware of their disagreement about the reliability of induction. $A^{*}$ trusts that induction is reliable (Q), while $\mathrm{B}^{*}$ trusts that induction is unreliable $(\sim \mathrm{Q})$. Moreover, $\mathrm{A}^{*}$ hasn't viciously avoided inquiry into whether induction is reliable, and neither of them have evidence sufficient for believing that induction is unreliable. However, B merely trusts that $\sim \mathrm{Q}$, as she has so far avoided inquiry into whether $\mathrm{Q}$, and has adopted trust that $\sim \mathrm{Q}$ because of her pessimistic psychological tendencies, saying that 'induction is unreliable'. Nevertheless, both $\mathrm{A}^{*}$ and $\mathrm{B} *$ believe many shared propositions on the basis of induction (e.g., the sun will rise tomorrow,

36 cf. Section 5.1. 
the trees near our communities will not start flying, etc.), and ordinarily employ inductive methods in their reasoning. $\mathrm{B}^{*}$ is just unaware of the fact that many of her beliefs and patterns of reasoning are based on or employ induction, while $\mathrm{A}^{*}$ is aware of this fact. Indeed, $\mathrm{A}^{*}$ and $\mathrm{B}^{*}$ trust all of the same hinge propositions, except for Q.

In this case, intuitively $A^{*}$ is entitled to trust induction. However, even though B* lacks evidence sufficient for her to believe that induction is reliable, given the entitlement theory, she nevertheless doesn't seem entitled to trust $\sim Q$, as it doesn't seem to her that she has evidence against $\mathrm{Q}$, and $\sim \mathrm{Q}$ doesn't seem to be part of her cognitive projects. Why? One reason is that $\mathrm{B}^{*}$ is already committed to trusting $\mathrm{Q}$ by her employment of induction and forming beliefs on the basis of induction. Indeed, trusting that $\mathrm{Q}$ is plausibly necessary for the success of the relevant cognitive projects she undertakes, as she merely fails to appreciate this fact, and continues to form beliefs on the basis of induction anyway. Prima facie, then, she ought to adopt trust in $\mathrm{Q}$, thereby rationally reaching agreement with $\mathrm{A}^{*}$. A second reason is that, although $\mathrm{B}^{*}$ trusts that $\sim \mathrm{Q}$, she's viciously avoiding inquiry about whether $\mathrm{Q}$, for she merely trusts $\sim \mathrm{Q}$ in the absence of inquiry. After all, she hasn't taken steps to investigate whether her individual procedures are cases of induction, and whether those cases have resulted in mostly true beliefs. Rather, she trusts $\sim \mathrm{Q}$ in virtue of her pessimistic psychological tendencies, such as her suspicion that the so far observed regularities in nature won't continue to hold. Hence, prima facie at least, there would be a rational resolution to their disagreement in propositional trust over a hinge proposition: both $\mathrm{A}^{*}$ and $\mathrm{B} *$ rationally ought to adopt trust towards Q. ${ }^{37,38}$

Now, you might worry that $\mathrm{B}^{*}$ has evidence which makes it rational for her to believe that $\mathrm{A}^{*}$ is not her epistemic peer, and thus that she's not rationally required to adopt trust toward $\mathrm{Q}$ as $\mathrm{A}^{*}$ is. However, this isn't right in this case because-unlike the spirit disagreement case- $\mathrm{B}^{*}$ doesn't have such peer-demoting evidence. In fact, $\mathrm{B}^{*}$ can rationally predict that, for many of the other hinge propositions $\mathrm{A}^{*}$ trusts, and many of the relevant beliefs that $A *$ has, they're likely to agree. That is, $B *$ won't have grounds sufficient for rationally believing that $A *$ is less likely to judge correctly in this case and related cases. Moreover, we might think that they'll be in a position to recognize their mutual commitment to $\mathrm{Q}$ in their dialogue over $\mathrm{Q}$ : perhaps such an exchange is the context that $\mathrm{B}^{*}$ needed to make manifest her entitlement to trust $\mathrm{Q}$.

\footnotetext{
37 Two salient questions: first, you might wonder whether updating trust attitudes is psychologically realistic, and, secondly, whether it would be similar to a conversion experience. The two questions are intimately connected, since it might be that even though a person rationally ought to give up their trust, psychologically it might be very difficult if it forms part of their worldview. In cases of deep disagreement, it seems more plausible that a change in trust would be similar to volitional conversion rather than non-volitional conversion, which requires time, cognitive effort, will and perhaps group-exiting. See Streib (2014) for discussions of the psychology of conversion.

38 Cf. Coliva (2015). Coliva argues that it's constitutive of rationality that we assume that our hinge propositions are true (Coliva 2015, p. 129). For example, the induction skeptic maintains that we cannot justifiably believe that induction is reliable, but yet even the skeptic will inevitably (if unwittingly) form inductively-based beliefs. Coliva's idea, I take, is that the inductive skeptic wants to have her cake and eat it too: to maintain that we can't justifiably believe that induction is reliable and yet to coherently employ induction anyway (see Coliva 2012, pp. 131, 156).
} 
To recap, I've argued that the entitlement account permits rational responses in certain cases of deep disagreement, and it permits rational resolutions in other cases of deep disagreement. The first kind of case is one in which the disputants trust different hinge propositions and are entitled to do so, despite the disclosure of their disagreement, whereas the second kind of case is one in which the disputants trust different hinge propositions, but both of them seem entitled to trust the same hinge proposition.

\section{Objections and Replies}

\subsection{Non-propositionalism}

Objection: Suppose that there can be disagreements in non-cognitive attitudes (Stevenson 1963). If this supposition is true, it's hard to see why one couldn't account for disagreement along non-propositionalist lines: they could just say that there are contrary pro-/con-attitudes that each participant maintains, constituting a disagreement, albeit one in non-cognitive attitude rather than doxastic attitude.

Reply: My argument is not for the view that there are no disagreements in noncognitive attitude. My view is rather that if non-propositionalism is the right account of hinge commitments, then it has highly revisionary consequences for our thinking about deep disagreement over the existence of the external physical world, the reliability of induction, and so on; consequences which I don't think are very plausible. My argument goes like this: in many cases of such disagreement, the apparently disagreeing parties provide what they take to be reasons for believing what they apparently take themselves to believe. However, if non-propositionalism were true, then in the relevant cases, either the apparently disagreeing parties are merely faultlessly disagreeing; or they aren't really providing reasons for their beliefs; or they don't really believe what they apparently take themselves to believe. This is a highly revisionary consequence. At the very least, we should place non-propositionalism on the back-burner until we've evaluated its competitors.

\subsection{Non-belief theory}

Objection: The non-belief theory seems to imply Moore-paradoxical propositions, such as that (i) "the Earth exists in the distant past, but I don't believe it" and (ii) "I'm convinced that the Earth exists in the distant past, but I don't believe it". However, (ii) sounds odd because semantically it expresses the idea that you believe that you are convinced that $\mathrm{P}$, but don't believe that $\mathrm{P}$. That might seem irrational, but the non-belief theory doesn't commit one to it being irrational: you can reasonably believe that you are convinced that $\mathrm{P}$, and yet reasonably believe that you don't believe that $\mathrm{P}$. And (i) sounds odd because it semantically expresses that you believe that P but that you don't believe that $\mathrm{P}$, which is irrational. Luckily, the non-belief theory denies the first conjunct (that you believe that $\mathrm{P}$, when $\mathrm{P}$ is a hinge proposition). So, the ascription of irrationality here is misguided. 
Reply: I gave two related arguments. The first was that assertions like "there is an external world, but I don't believe it" sound paradoxical (Moore-paradoxical), and it's hard to see what resources the non-belief theory has to explain this. They can say that it sounds paradoxical on the grounds that the sentence semantically expresses the conjunction that you believe there is an external world, but don't believe that there is - which is a contradiction-but then they shoot themselves in the foot: for then the assertion of "there is an external world" would need to be understood as expressing the belief that there is an external world, which would come out false on their account (since you can't believe it, on their account). They could go the route that when you assert such a sentence, you pragmatically imply that you believe the first conjunct, but then that gives us an irrational verdict as well: were you ever to assert "there is an external world" (as Moore did), you would be implying to the listener that you believe what you said, when, given the non-belief theory, you don't.

My second argument was that the person who came to see that they were only merely convinced that $\mathrm{P}$ whilst not having any reason whatsoever to believe that $\mathrm{P}$ epistemically shouldn't retain their conviction; that doing so would be epistemically irrational. I can't see why, provided there are epistemic norms regulating our doxastic attitudes, it doesn't regulate conviction that $\mathrm{P}$ in such a way that the higher-order evidence that you lack epistemic reasons for $P$ shouldn't obligate you to give up your conviction. Maybe one could say that Pritchard's (2016) account shows that you can be convinced while recognizing that conviction isn't subject to epistemic rationality norms, but the onus is on the non-belief theorist to explain why that is. Intuitively, if I'm convinced that P and you give me a defeater for P, I shouldn't be convinced any longer. ${ }^{39}$

\subsection{Entitlement theory}

Objection: If people can be entitled to trust different, contrary hinge commitments, doesn't this support epistemic relativism, the thesis that "cognitive norms that determine what counts as knowledge, or whether a belief is rational, justifiable, etc. could vary with and are dependent on local conceptual or cultural frameworks and lack the universality they aspire or pretend to"? (Baghramian and Carter 2017) For example, imagine A says to B "you're irrational in your trust that there are no spirits", while B says to A "you're irrational in your trust in the existence of spirits". This looks like a disagreement. However, if epistemic relativism is true, then they're both right according to their contrary epistemic systems. But then it's not obviously a genuine disagreement.

Reply: The proponent of the entitlement strategy has two options. The first option would be to simply embrace epistemic relativism (Hazlett 2013; Kusch 2016, 2017). In turn, the charge from person A to B that "you're irrational in your trust" would be true, and the charge from person B to A that "you're irrational in your trust" would be true as well. So, they don't really disagree in that case: they're both right, after all. And so the question of rationally resolving the disagreement isn't apt here. Rather, they both have a rational response to their apparent disagreement: A truthfully says 'I'm entitled to

39 Thanks to Mark Walker for pressing the point. 
trust that there are spirits", while B truthfully says "I'm entitled to trust that there are no spirits"; neither of them would be irrational here. However, it's important to notice that this isn't the first-order disagreement we began with (Sect. 5), but rather a higher-order disagreement. The initial disagreement was: this $\mathrm{A}$ trusts that $\mathrm{P}$, while $\mathrm{B}$ trusts that $\sim \mathrm{P}$, but the higher-order disagreement is that A believes ' $\mathrm{B}$ is not rational in trusting that $\sim \mathrm{P}$ ', while $\mathrm{B}$ believes ' $\mathrm{A}$ is not rational in trusting that $\mathrm{P}$ '. The relativistic entitlement theorists could say that the higher-order disagreement is merely faultless, and thus not a genuine disagreement, but this wouldn't entail that the first-order disagreement is merely apparent or faultless. Or they could say that A and B can mutually recognize that they're conditionally rational: given A's framework, she's rational in believing that B's trust that $\sim \mathrm{P}$ is irrational, while, given B's framework, she's rational in believing that A's trust that P is irrational (see Hazlett 2013, pp. 12-13). The other option is to hold that hinge propositions are universal - that if $p$ is a hinge proposition, then $\neg p$ or anything inconsistent with it is not a hinge proposition-and insist that only one of them could be right: that entitlement to trust only holds between a person and a certain set of propositions. The dispute then would be over which propositions those are, and would thus become a higher-order disagreement over which propositions have the status of being hinge propositions. And the proponent of the entitlement strategy would need to motivate which propositions they are, based on what makes one better off epistemically, given any cognitive project. Good candidates here include what Pritchard (2016) calls the "über hinge commitment", that you aren't radically and systematically deceived.

\section{Conclusion}

In this paper, I applied hinge epistemology to the case of deep disagreement. In particular, I considered the question of whether deep disagreements are rationally resolvable in light of the Wittgensteinian account of deep disagreement. I argued that on many ways of developing the theory of hinge commitments, the Wittgensteinian account would adequately support a radical pessimistic answer to this question (Sects. 2-4). Specifically, mainstream non-epistemic theories of hinge commitments, such as the non-propositional and the non-belief theories, seemed to adequately support the thesis that not only are disagreements over hinge commitments not rationally resolvable, but not even subject to rational responses, such that the disputants can rationally take contrary attitudes to the hinges. However, I argued that strictly speaking the Wittgensteinian account can be consistently combined with optimism about deep disagreement (Sect. 5). This is because there can be cases in which the disputants are rationally entitled, even after the disclosure of their disagreement, to trust competing hinge propositions, and there can be cases in which both disputants ought to trust the same hinge proposition (Sect. 5.2).

Finally, while the Wittgensteinian theory alone doesn't adequately support pessimistic views about deep disagreement, that many ways of developing it do seem to support it ought to make us look more critically at the theory. First, because one might think that pessimism about deep disagreement is an intolerable consequence-that surely such disagreements can be rationally resolved or rationally responded to. And, 
secondly, since non-epistemicism has many implausible consequences in the case of disagreement, this puts considerable pressure on hinge epistemologists to reject the non-epistemic theory. As we've seen, hinge epistemology is mainly pessimistic about deep disagreement, but strictly speaking hinge epistemology has optimistic options.

Acknowledgements I would like to thank Dominik Balg, Jan Constantin, Thomas Grundmann, Thirza Lagewaard, Jeroen de Ridder, Mark Walker, and René van Woudenberg for their helpful feedback on earlier versions of this paper. I would also like to thank two anonymous referees at Synthese for their really helpful comments which greatly improved the paper. Finally, I want to thank the audiences at the Epistemic Dynamics of Disagreement conference at the University of Cologne, the guest speaker seminar at the University of Tilburg, and the members of the theoretical philosophy research group at the VU University Amsterdam for helpful feedback on earlier versions of this paper. Research for this paper was supported through a Vidi grant (276-20-024) from the Netherlands Organization for Scientific Research.

Open Access This article is distributed under the terms of the Creative Commons Attribution 4.0 International License (http://creativecommons.org/licenses/by/4.0/), which permits unrestricted use, distribution, and reproduction in any medium, provided you give appropriate credit to the original author(s) and the source, provide a link to the Creative Commons license, and indicate if changes were made.

\section{References}

Adams, D. M. (2005). Knowing when disagreements are deep. Informal Logic, 25(1), 65-77.

Baghramian, M., \& Carter, J. A. (2017). Relativism. In The stanford encyclopedia of philosophy (Summer 2017 Edition), Edward N. Zalta (ed.).

Barkun, M. (2003). A culture of conspiracy. Berkeley, CA: University of California Press.

Brueckner, A. (2007). Hinge propositions and epistemic justification. Pacific Philosophical Quarterly, $88(3), 285-287$.

Campolo, C. (2009). Deep disagreement in a multicultural world. In J. Ritola et al (Eds.), Argument cultures: Proceedings of the 8th Ontario Society for the Study of Argumentation (OSSA) Conference, June 3-6, 2009. ON: OSSA Windsor.

Chrisman, M. (2012). Epistemic expressivism. Philosophy Compass, 7(2), 118-126.

Christensen, D. (2007). Epistemology of disagreement: The good news. Philosophical Review, 116(2), $187-217$.

Coliva, A. (2015). Extended rationality: A hinge epistemology. UK: Palgrave Macmillan.

Feldman, R. (2005). Deep disagreement, rational resolutions, and critical thinking. Informal Logic, 25(1), $12-23$.

Feldman, R. (2006). Epistemological puzzles about disagreement. In S. Hetherington (Ed.), Epistemology futures (pp. 216-236). New York: Oxford University Press.

Feldman, R. (2007). Reasonable religious disagreements. In L. Antony (Ed.), Philosophers without gods (pp. 194-214). Oxford: Oxford University Press.

Fogelin, R. (1985 [2005]). The logic of deep disagreements. Informal Logic 7(1), 3-11.

Friedman, J. (2013). Suspended judgment. Philosophical Studies, 162(2), 165-181.

Godden, D., \& Brenner, W. H. (2010). Wittgenstein and the logic of deep disagreement. Cogency: Journal of Reasoning and Argumentation, 2, 41-80.

Hazlett, A. (2006). How to defeat belief in the external world. Pacific Philosophical Quarterly, 87(2), $198-212$.

Hazlett, A. (2013). Entitlement and mutually recognized reasonable disagreement. Episteme, 1, 1-25.

Jenkins, C. (2007). Entitlement and rationality. Synthese, 157(1), 25-45.

Kappel, K. (2012). The problem of deep disagreement. Discipline Filosofiche, 22(2), 7-25.

Kappel, K. (forthcoming). Higher order evidence and deep disagreement. Topoi.

Kappel, K., \& Jønch-Clausen, K. (2015). Social epistemic liberalism and the problem of deep epistemic disagreements. Ethical Theory and Moral Practice, 18(2), 371-384.

Kelly, T. (2013). Disagreement and the Burdens of Judgment. In D. Christensen \& J. Lackey (Eds.), The epistemology of disagreement: New essays (pp. 31-53). Oxford: Oxford University Press. 
Kornblith, H. (2015). The role of reasons in epistemology. Episteme, 12(2), 225-239.

Kusch, M. (2016). Wittgenstein's on certainty and relativism. In H. A. Wiltsche \& S. Rinofner-Kreidl (Eds.), Analytic and continental philosophy: Methods and perspectives. Proceedings of the 37th international wittgenstein symposium. De Gruyter. pp. 29-46.

Kusch, M. (2017). Epistemic relativism, scepticism, pluralism. Synthese, 194(12), 4687-4703.

Lynch, M. (2010). Epistemic circularity and epistemic disagreement. In A. Haddock, A. Millar, \& D. Pritchard (Eds.), Social epistemology. Oxford: Oxford University Press.

Lynch, M. (2016). After the spade turns: Disagreement, first principles and epistemic contractarianism. International Journal for the Study of Skepticism, 6, 248-259.

MacFarlane, J. (2014). Assessment sensitivity: Relative truth and its applications. Oxford University Press.

Marques, T. (2014). Doxastic disagreement. Erkenntnis, 79(S1), 121-142.

Matheson, J. (2018). Deep disagreements and rational resolution. Topoi. https://doi.org/10.1007/s11245-0 18-9576-y.

Moyal-Sharrock, D. (2004). Understanding Wittgenstein's on certainty. London: Palgrave Macmillan.

Moyal-Sharrock, D. (2016). The animal in epistemology. International Journal for the Study of Skepticism, 6, 97-119.

Pedersen, N. J. (2009). Entitlement, value, and rationality. Synthese, 171, 443.

Phillips, D. (2008). Investigating the shared background requirement for argument: A critique of Fogelin's thesis on deep disagreement. Informal Logic, 28(2), 86-101.

Pritchard, D. (2009). Defusing epistemic relativism. Synthese, 166, 397-412.

Pritchard, D. (2011a). Wittgenstein on Scepticism. In O. Kuusela \& M. McGinn (Eds.), The oxford handbook of Wittgenstein (pp. 521-547). Oxford: Oxford University Press.

Pritchard, D. (2011b). Relativism, epistemic incommensurability, and Wittgensteinian epistemology. In S. D. Hales (Ed.), The Blackwell companion to relativism (pp. 266-285). London: Wiley-Blackwell. https://doi.org/10.1002/9781444392494.ch14.

Pritchard, D. (2011c). Wittgensteinian Pyrrhonism. In D. E. Machuca (Ed.), Pyrrhonism in ancient, modern, and contemporary philosophy (pp. 193-202). Dordrecht: Springer.

Pritchard, D. (2016). Epistemic angst: Radical skepticism and the groundlessness of our believing. Princeton, NJ: Princeton University Press.

Pritchard, D. (2018). Epistemic angst. Philosophy and Phenomenological Research. https://doi.org/10.111 1/phpr.12280.

Pritchard, D. (forthcoming). Disagreement, of belief and otherwise. In: C. Johnson (Ed.) Voicing dissent, London: Routledge.

Ranalli, C. (forthcoming). What is deep disagreement? In Topoi, SPECIAL issue: Disagreement: Perspectives from Argumentation Theory and Epistemology.

Raz, J. (2011). From normativity to responsibility. Oxford: Oxford University Press.

Ridge, M. (2012). Disagreement. Philosophy and Phenomenological Research, vol. LXXXVI, No. 1, 41-63.

Ridge, M. (2014). Impassioned belief. Oxford: Oxford University Press.

Stevenson, C. (1944). Ethics and language. New Haven: Yale University Press.

Stevenson, C. (1963). Facts and values. New Haven: Yale University Press.

Streib, H. (2014). Deconversion. In L. R. Rambo \& C. E. Farhadian (Eds.), Oxford handbook on religious conversion (pp. 271-296). Oxford University Press.

Stroud, B. (2000). Understanding human knowledge: Philosophical essays. Oxford: Oxford University Press.

Sylvan, K. (2016). Epistemic reasons I: Normativity. Philosophy Compass, 11(7), 364-376.

Turner, D., \& Wright, L. (2005). Revisiting deep disagreement. Informal Logic, 21, 25-35.

Williams, B. (1985). Ethics and the Limits of Philosophy. Harvard University Press.

Wittgenstein, L. (1969). On certainty. In G. E. M Anscombe, G. H. von Wright, D. Paul and G. E. M. Anscombe (Eds.). Oxford: Blackwell.

Wright, C. (1985). Facts and certainty. Proceedings of the British Academy, 71, 429-472.

Wright, C. (2004a). Warrant for nothing (and foundations for free)? Aristotelian Society Supplementary, $78(1), 167-212$.

Wright, C. (2004b). Wittgensteinian certainties. In D. McManus (Ed.), Wittgenstein and Scepticism (pp. 22-55). London: Routledge.

Wright, C. (2014). On epistemic entitlement II: Welfare state epistemology. In D. Dodd \& E. Zardini (Eds.), Scepticism and perceptual justification. Oxford: Oxford University Press. 